\title{
DO CENTRO À PERIFERIA DO PODER
}

Tiago Ribeiro dos Santos

Mestrando em Literatura - UFSC

\begin{abstract}
RESUMO
As negociações que se instauram no centro e, principalmente, nas fronteiras das formações sociais, sempre atravessadas por questões de gênero, classe, raça e sexualidade podem ser verificadas no campo das representações artísticas em geral, sobretudo nas filmografias que marcam a história de sujeitos diaspóricos, que fazem do próprio trânsito um entre-lugar, marcado ora por ações de revolta e resistência, ora por ações de total submissão. Este artigo aborda uma discussão acerca do discurso colonial (e eurocêntrico) e de sua representação em duas narrativas cinematográficas. Nos filmes Amélia e $O$ Piano procura-se evidenciar os momentos de tensão e de resistência entre culturas diferentes, a partir do conceito de Tradução Cultural na perspectiva de Homi Bhabha.
\end{abstract}

PALAVRAS-CHAVE

Discurso colonial; Cinema; Tradução Cultural.

\section{FROM THE CENTER TO THE PERIPHERY OF POWER}

\begin{abstract}
Negotiations are being established in the center and especially at the borders of social formations, where crossed by gender, class, race and sexuality is evident in the field of artistic performances in general, especially in the filmographies that mark the history of diasporic subjects, forming one's own transit-between place, marked either by actions of revolt and resistance, or by shares of total submission. This article performs a discussion of colonial discourse (and eurocentric) and its representation in two film narratives. In the film Amelia and The Piano, seeks to highlight the moments of tension and resistance between different cultures, from the concept of Cultural Translation in the perspective of Homi Bhabha.
\end{abstract}




\section{KEYWORDS}

Speech colonial; Cinema; Cultural Translation.

Se considerarmos a grande variedade de recursos de que o cinema dispõe para aparentemente contar apenas uma história, bem como as inúmeras possibilidades de combinação do seu material expressivo, percebemos que a chamada sétima arte funciona como um locus de tensão, onde estão representadas estruturas de poder capazes de veicular diferentes tipos de discurso. As narrativas cinematográficas, como textos significantes, da mesma forma que podem ser construídas e estruturadas de acordo com múltiplas possibilidades sintáticas e semânticas, também apresentam discursos dotados de uma carga social, cultural e psicológica. Mesmo valendo-se de recursos como a música e a multiplicidade de imagens, à natureza audiovisual do cinema junta-se a utilização da linguagem, cuja capacidade de veiculação de ideologias é inerente ao próprio ato de enunciação das personagens. Como não há discurso no mundo que não seja carregado de carga ideológica e que não isente o sujeito enunciador em relação ao compromisso que mantém com seu enunciado, podemos afirmar que não há arte cinematográfica descompromissada, de modo a pensar o cinema somente como a arte do deleite.

Da mesma forma que Bakhtin utiliza a noção de carnavalização $o^{l}$ para estudar o objeto literário, podemos associá-la à análise de muitas narrativas cinematográficas que rejeitam a "harmonia" dos discursos veiculados pelas instituições de poder, em prol da inversão de valores e da veiculação de discursos de classes minoritárias. Dessa forma, alguns filmes apresentam momentos de resistência em relação a valores e discursos dominantes, revelando o grotesco dos poderosos e a beleza do que é tido como vulgar. Esses filmes redimensionam e remodelam as práticas hierárquicas, elaborando uma estética que se opõe aos discursos vigentes, a partir da criação de discursos carnavalizados, que visam à desmistificação de um olhar legitimado por estruturas de poder. Se o Carnaval, para Bakhtin, é tido como o período em que as distinções hierárquicas, barreiras, normas e proibições são temporariamente suspensas, alguns filmes também podem ser tidos como espaços onde a "normalidade" do discurso

\footnotetext{
${ }^{1}$ Cf. a noção de carnavalização em: BAKHTIN, Mikhail. Problemas da Poética de Dostoiévski. Tradução de Paulo Bezerra. Rio de Janeiro: Ed. Forense Universitária, 2005.
} 
eurocêntrico se altera, fazendo emergir vozes dissonantes que costumeiramente permanecem caladas.

No ínterim dos discursos que se pretendem dominantes, temos o processo de formação do discurso colonial, pelo qual o Ocidente produziu uma ideia sobre si, para si mesmo e para o restante do mundo. De acordo com as formulações do pensamento crítico sobre as zonas de contato - como espaços de negociação -, ou seja, sobre a história do contato entre a Europa e outros países do mundo, como os do continente africano e asiático, assinala Mary Pratt:

Enfocando inicialmente os meios pelos quais a Europa (a Euro-América) vem representando outros para si mesma, os estudos do discurso colonial assumiram uma perspectiva sobre o ocidente em suas relações com outras partes do mundo. Essa atitude se contrapõe à visão difusionista ortodoxa, que vê o ocidente como uma emergência sui generis, e a difusão em si como capital, como império, como civilização. (PRATT, 1999, p. 16).

De acordo com Pratt, foi a partir do impacto causado na academia ocidental por intelectuais africanos, asiáticos e latinoamericanos que o discurso colonial passou a ser questionado enquanto produto de uma visão eurocêntrica. A hegemonia criada pela Europa nos âmbitos econômico, militar, político e cultural nos povos colonizados corroborou para a criação de um regime de verdade e poder, que começou a ser desmistificado somente após a desintegração dos impérios coloniais. Enquanto centro de poder, a Europa criou para si mesma e para o restante do mundo a ideia de civilização, a qual deu origem a um discurso maniqueísta e a uma série de dicotomias, que marcam a civilização versus a barbárie, o culto versus o inculto, o superior versus o inferior. Esse discurso eurocêntrico, na verdade, não passa de uma invenção europeia como forma de marcar sua superioridade e forjar uma vocação nata para a supremacia nos vários âmbitos do poder. A respeito dos discursos colonialistas e eurocêntricos, assinala Ella Shohat:

Com base ideológica comum ao colonialismo, ao imperialismo e ao discurso racista, o eurocentrismo é uma forma de pensar que permeia e estrutura práticas e representações contemporâneas mesmo após o término oficial do colonialismo. Embora os discursos colonialistas e eurocêntricos estejam intimamente relacionados, suas ênfases são distintas. Enquanto o primeiro justifica de forma explícita as práticas colonialistas, o outro "normaliza" as relações de hierarquia e poder geradas pelo colonialismo e pelo imperialismo, sem necessariamente falar diretamente sobre tais operações. (SHOHAT e STAM, 2006, p. 21). 
De acordo com Ella Shohat e Robert Stam, "o eurocentrismo contemporâneo é o resíduo discursivo ou a sedimentação do colonialismo" (SHOHAT e STAM, 2006, p. 40) e está presente nas práticas culturais, inclusive no cinema, de um modo que reproduz, muitas vezes, o mesmo discurso colonial em tempos de globalização. Sob o crivo de neocolonial, esse discurso agora está presente em formas de controle abstratas e indiretas, geralmente de natureza econômica e cultural. É o que pode ser verificado em algumas narrativas cinematográficas produzidas nos Estados Unidos, de acordo com o rótulo hollywoodianismo, um outro nome para eurocentrismo, segundo os dois autores. Apesar de contribuir com apenas uma parte da produção do cinema mundial, a cinematografia hollywoodiana apresenta uma posição hegemônica e poda a participação do cinema de outros países. Ainda hoje, em tempos de cultura nacional e transnacional, perdura em algumas cinematografias produzidas no contexto dos países de primeiro mundo uma perspectiva eurocêntrica e um olhar colonial em relação aos povos colonizados do terceiro mundo. Conforme assinala Robert Stam:

O cinema combinou narrativa e espetáculo para narrar a história do colonialismo do ponto de vista do colonizador. Ou seja, o cinema dominante falou pelos "vencedores" da história, em uma filmografia que idealizava a empresa colonial como uma missão civilizatória filantrópica motivada pelo desejo de avançar sobre as fronteiras da ignorância, da tirania e da doença. As representações programaticamente negativas das colônias ajudavam a racionalizar os custos humanos do empreendimento imperialista. (STAM, 2003, p. 34).

De acordo com Shohat e Stam, a expressão terceiro mundo, utilizada para designar as "minorias" colonizadas cuja estrutura política e social foram constituídas a partir do colonialismo, é problemática e escorregadia, já que, além de englobar todas as nações sob o manto do atraso e do subdesenvolvimento, não leva em conta as particularidades de cada país, escondendo contradições e obnubilando as marcas da heterogeneidade. É preciso, antes de tudo, assumir que existem "fissuras sociais e ideológicas no interior das nações do Terceiro Mundo" (STAM, 2003, p. 309) e que não há uma linha demarcatória entre o Primeiro e o Terceiro Mundo. No novo regime marcado pela globalização, o Primeiro e o Terceiro Mundo estão imbricados e o teor dos discursos binaristas marcado pelas condições de opressor e oprimido cede lugar a uma visão de intensa negociação, que não mascara as instâncias de poder, mas que leva em conta, sobretudo, as tensões relativas à classe, raça, sexualidade e ao gênero. Nesse sentido, as negociações que se instauram no centro e, principalmente, nas fronteiras das 
formações sociais, sempre atravessadas pelas tensões a que nos referimos, fica evidente no campo das representações artísticas em geral, sobretudo nas filmografias que marcam a história de sujeitos diaspóricos, que fazem do próprio trânsito um entre-lugar, marcado ora por ações de revolta e resistência, ora por ações de total submissão.

$\mathrm{Na}$ ótica dos discursos coloniais evocados nos filmes The Piano ${ }^{2}$ e Amélia $^{3}$, tentaremos investigar de que forma operam as tensões e os momentos de negociação, levando em consideração o contexto de produção e de recepção de cada um deles. De acordo com Stam, ao propor que "se, por um lado, o cinema é mimese e representação, por outro, é também enunciado, um ato de interlocução contextualizada entre produtores e receptores socialmente localizados. Não basta dizer que a arte é construída. Temos de perguntar: Construída para quem e em conjunção com quais ideologias e discursos?" (STAM, 2003, p. 305) é preciso pensar em The Piano como uma produção do cinema norteamericano, portanto de caráter hegemônico se comparado às cinematografias de outros países, sobretudo em relação a Amélia, filme produzido por uma diretora brasileira no contexto do cinema latinoamericano. The Piano, lançado em 1993, é ambientado em meados do século XIX na Nova Zelândia e retrata, em plena era vitoriana, a colonização inglesa da população indígena da região da Polinésia. Os maori, como são conhecidos os habitantes nativos, têm suas terras apropriadas pelas "normas" britânicas, representadas por Stewart, que se casa com a escocesa Ada - mãe solteira de uma criança - e a leva para a terra recém-colonizada da Nova Zelândia. Ada é muda e leva consigo na mudança seu piano, objeto que é o fio condutor da narrativa e que serve como peça de agenciamento das relações sociais e amorosas abordadas no filme.

Ao ser inserida no novo espaço imperialista, marcado pelo puritanismo, cobiça e violência do colonizador, Ada envolve-se com George Baines, um tribalizado europeu que clama pelo seu amor. A personagem de Baines é representativa das relações amistosas que alguns britânicos conseguiam manter com os nativos, inclusive com a incorporação de traços culturais dos maori. No entanto, isso não quer dizer que não havia tensões que colocavam em xeque o desejo imperialista de apropriação do território, por parte dos britânicos, e o desejo de viver em liberdade na terra natal, por parte dos indígenas.

Mais do que simplesmente contar a história de um triângulo amoroso, The Piano suscita questões em torno da marginalização da população indígena no seu

\footnotetext{
${ }^{2}$ Filme produzido em 1993 nos Estados Unidos, sob a direção de Jane Campion.

${ }^{3}$ Filme brasileiro da diretora Ana Carolina, produzido em 2000.
} 
próprio território, mascarada por um discurso colonial que visa a contar os fatos sob a ótica do colonizador, escondendo todas as mazelas da empreitada imperialista e todas as consequências resultantes deste processo. $\mathrm{O}$ filme aborda a população indígena como um povo ligado à sua terra e intocado pela "complexidade" do progresso sem, sequer, dar voz às personagens maori. Como assinala Caroline Brown: "They are the repositories of truth and purity bound to the land, untouched by the contradictions and complexity of progress. Eroticized objects of a feminine gaze, they do not stand on their own as fully formed characters.” (BROWN, 2003. p. 15)

Num ambiente marcado sobretudo pelo servilismo ao representante do sexo masculino, é o homem branco quem fala e quem define as regras das práticas cotidianas. Os homens e as mulheres maori ocupam em The Piano as mesmas funções usualmente ocupadas pelos homens e mulheres na sociedade branca. Assim, percebemos os homens da tribo ocupando funções de poder, pois são eles que negociam com Stewart a venda das terras; ao passo que as mulheres sempre aparecem ocupadas com afazeres domésticos, do mesmo modo que as mulheres nas sociedades brancas.

O contraste cultural entre o homem branco e os maori aparece claramente na cena em que Stewart negocia com os indígenas oferecendo armas em troca das terras. Como resposta, os maori afirmam que não há nada que possa pagar as terras onde estão enterrados seus antepassados. Além de The Piano suscitar discussões em torno do poder do homem branco sobre a população maori recém-colonizada, esse filme ainda gera uma reflexão acerca de gênero, uma vez que este é um dos fatores que se chocam no processo de negociação das diferenças entre as personagens. Ada, a mãe escocesa da menina que traduz suas falas (quando não se expressa por meio do piano, é a menina a responsável por traduzir as falas da mãe), casa-se com Stewart e vai viver em sua companhia numa terra dominada por representantes do sexo masculino. Na dominação inglesa da Nova Zelândia do final do século XIX são os homens quem ditam as regras. No entanto, a narrativa fílmica desenvolve-se a partir de Ada, a representante do sexo feminino e o lugar-comum para onde convergem todas as tensões.

No início do filme já se instala uma tentativa de negociação entre Ada e seu marido Stewart, cuja relação conjugal é de muita formalidade, já que Ada e o marido são oriundos de países diferentes. É esperado de Ada que se submeta às regras do patriarcalismo e do puritanismo, elementos contidos no processo colonial britânico, mas a personagem em alguns momentos resiste a servir de peça desta complexa engrenagem e do poder mantido por Stewart. Por isso, o espaço cênico de The Piano é um lugar 
marcado eminentemente como palco de revolta da protagonista feminina. Esse espaço de revolta é marcado sobretudo pela dificuldade de Ada em manter o servilismo ao marido, cujo rompimento se dá com a relação adúltera entre ela e George Baines.

Em oposição a Stewart, Baines é o "nativo simbólico" do filme, um homem traduzido $^{4}$, pelo fato de incorporar traços da cultura maori. Conforme assinala Caroline Brown:

\begin{abstract}
There is a significant role reversal that takes place between the whites and the Maoris. It is Ada who is mute, though she narrates the film in voice-over. The white husband, shunned by her, is portrayed as emotionally rigid and emasculated, so repressed as to lack an appealing sexuality. Baines, acting as intermediary between the colonial whites and the Maori, with whom he lives but does not cohabit, is hypermasculine. His body, tattooed and darkened by exposure to the elements, is firm and muscled like those of his Maori counterparts, unlike the pale, soft, cosseted body of the rejected Stewart. He becomes the symbolic native whom Ada comes to desire. (BROWN, 2003, p. 11)
\end{abstract}

A figura muito emblemática de George Baines, o amante, mostra como o homem branco, ao conviver um longo tempo com os nativos, apropria-se de algumas marcas próprias dos maori, como as pinturas na face. Isso comprova que o processo de tradução cultural, segundo o conceito formulado por Homi Bhabha, não é unidirecional, ou seja, tanto os brancos como os nativos são vítimas deste processo que ocorre no espaço de fissura entre uma cultura e outra. É neste "terceiro espaço" que os valores das duas culturas são revistos e as diferenças são negociadas, como ocorre com o "nativo simbólico" Baines - um personagem no entre-lugar de duas culturas que, após tomar posse do piano em troca das terras cedidas ao marido de Ada, faz do objeto que funciona como o fio condutor da narrativa fílmica um objeto de manipulação. É por meio do "escambo" realizado entre Ada e George que ela entrega-se a ele, fazendo desta entrega um símbolo de negociação das diferenças.

A priori, podemos pensar no fato de George apossar-se do piano para manipular Ada como sendo um momento de resistência a um olhar dominante (leia-se eurocêntrico), uma vez que os papéis se invertem: Ada, a representante da cultura europeia por excelência está numa posição de subalternidade, enquanto George - o nativo simbólico - está com o poder nas mãos. No entanto, o objeto desencadeador do

\footnotetext{
4 Partimos do conceito de Tradução Cultural de Homi Bhabha, que prevê que os símbolos de uma cultura quando são "negociados" e recolocados numa nova cultura sofrem um processo de "ressignificação". É no espaço intersticial ou "terceiro espaço" e a partir de uma experiência de travessia que os símbolos ganham novos significados. Cf. o texto de Bhabha: The Vernacular Cosmopolitan. In: DENNIS, F.; KHAN, N. (org.). Voices of the Crossing. Serpent's Tail, 2000.
} 
poder temporário de George é genuinamente produto da cultura europeia e permanece sob o seu poder durante pouco tempo. A subalternidade de Ada revela-se quando Baines, representante da cultura negociada entre brancos e nativos, assume a posição de voyer, já que Ada tem seu corpo visto como objeto erótico que também tem de ser negociado. A abordagem de The Piano quanto ao agenciamento das relações de poder, atravessadas por diferenças de raça, cultura e gênero, deixa entrever sistemas ideológicos de subordinação feminina, em que é sempre o corpo da mulher, e não o do homem, o alvo de acirradas tensões e disputas. De acordo com o pensamento de Caroline Brown:

She [Jane Campion] teases the spectator by mixing narrative forms that veer from the assertively feminist to a Victorian pastoral with undertones of the true woman. In doing so, however, Campion reveals the fault lines around race, sex, the consumption of the female body, and the tensions around the creation of new discourses in film. (BROWN, 2003, p. 10)

A espécie de "escambo", que ocorre no filme, já que o objeto de poder que pertence a Ada (o piano) permanece por algum tempo nas mãos de Baines, é o resultado da tensão exercida pelo corpo da mulher, que encara o jogo sexual de George como forma de recuperar o objeto alvo de seu desejo. Nesse jogo sexual amplamente erotizado, percebemos que a própria linguagem corporal de Ada e Baines é capaz de comunicar hierarquias sociais e a servilidade por parte de Ada para recuperar o piano. Nessa relação em que o corpo da mulher branca europeia torna-se mercadoria de troca e de tensão constante, constatamos claramente a diferença entre corpos que, esteticamente, se opõem para comunicar diferenças mais profundas. Nesse ínterim, vemos que o corpo também é capaz de marcar o poder e a subalternidade, pois, numa sociedade dominada pela voz masculina, o corpo da mulher é passível de negociação. De acordo com Caroline Brown, os corpos de Ada e Baines evidenciam algumas destas questões:

Rather, Baines, like Campion, is blinded and enraptured by Ada's whiteness, a rare commodity, in a land where whiteness comes to represent an object of startling uniqueness and value. Simultaneously, Baines, as exoticized white, becomes an object of erotic fascination, particularly in the tight focus of the camera on his naked and vulnerable body. His is the Other body the audience actually perceives. While we stare in erotic fascination, his sexuality, which nurtures Ada's into existence, intensifi es the ascendance of European

\footnotetext{
${ }^{5}$ Definimos a relação inicial de Ada e Baines como uma forma de escambo, espécie de troca de mercadorias por trabalho muito utilizada no contexto da colonização.
} 
culture. Campion relies on the Maoris to provide the spaces of ambiguity that will propel her tale of the reconstitution of the white family according to a more liberated gender and sexual ideal. (BROWN, 2003, p. 14)

O corpo "negociado" de Ada, da mesma forma que é utilizado por Baines como objeto erótico alvo de desejo, é também alvo de punição, quando Stewart descobre a relação adúltera de sua esposa. O dedo decapitado de Ada, cuja cena relê na esfera da violência e da selvageria por parte do homem branco, a mesma cena representada no teatro de sombras, era o instrumento que lhe permitia falar por meio do piano. Stewart, ao expressar o ressentimento oriundo da traição, acaba por fazer do dedo de sua esposa - o símbolo fálico presente na relação entre ela e Baines -, o objeto da violência masculina. Nas palavras de Caroline Brown, "Their relationship is consummated which eventually leads to their discovery by Stewart who severs Ada's finger, the phallic symbol through which she asserts her individuality." (BROWN, 2003, p. 12). A mulher, além de ter seu corpo utilizado como mercadoria de troca, tem parte dele mutilado em decorrência da violência de um sistema marcado pela presença dominadora do homem.

Da mesma forma que The Piano pode ser analisado sob a ótica dos discursos coloniais, Amélia (2000), um filme brasileiro da diretora Ana Carolina, também evoca discussões no âmbito das diferenças culturais, uma vez que as personagens estão em constante tensão num determinado espaço de poder. A diretora lança mão de um fato real, a visita da atriz Sarah Bernhardt ao Brasil em 1905, com o objetivo de apresentar a peça Tosca no Rio de Janeiro. A atriz sofreu um acidente no ato final do espetáculo, pois numa cena em que teria de pular de um alto muro, ela teve seu joelho machucado. Ana Carolina apropria-se deste fato para compor a narrativa cinematográfica de Amélia, cujo título faz menção ao nome da protagonista, a camareira brasileira da atriz Sarah Bernhardt. A personagem Amélia convence a atriz francesa a vir apresentar o espetáculo Tosca no Brasil e envia uma carta às suas irmãs - Francisca e Oswalda residentes no interior de Minas Gerais, para que viajem ao Rio de Janeiro para encontrála e para que sejam as costureiras de Sarah durante sua estada no Brasil. Na carta, Amélia também exprime seu desejo pela venda das terras de "águas milagrosas" de Cambuquira, onde suas irmãs residem, para que seja dividida a herança de família. Francisca e Oswalda, atendendo ao pedido de Amélia, decidem se deslocar até o Rio de Janeiro e levam consigo a agregada Maria Luiza. Na chegada ao hotel em que se 
hospedam, as irmãs são informadas de que Amélia contraíra uma febre e morrera em Buenos Aires, onde fora enterrada.

É preciso perceber, antes de tudo, que Amélia, além de evocar discussões no âmbito do discurso colonial, como afirma Souza,

\begin{abstract}
No caso da representação do colonizado na literatura colonial e pós-colonial, é o (ex) colonizador que geralmente lança mão da análise de imagens para reafirmar uma transcendência etnocêntrica, resultando em imagens do colonizado racistas e discriminatórias, porém vistas como verdadeiras e autênticas. (SOUZA, 2004, p. 116)
\end{abstract}

uma vez que há uma mostra explícita de como o representante da cultura francesa acredita (e faz acreditar) na sua superioridade cultural, ainda gera reflexões no âmbito do gênero, pois são mulheres que tentam negociar suas diferenças num mundo marcado pela presença opressora do masculino.

No início do filme, na carta remetida às irmãs do interior de Minas, Amélia expressa repugnância pelo ambiente do interior mineiro. A figura emblemática de Amélia, que só se faz presente no início da narrativa fílmica para depois se transformar em memória pelas irmãs e por Sarah Bernhardt, pode ser tida como a personagem que assimilou a cultura europeia para, inclusive, olhar com desprezo para a sua cultura de origem. De acordo com Santos, a personagem Amélia é o fio condutor do filme:

\footnotetext{
O fantasma de Amélia guia toda a trama. É ela quem conduz e propicia o encontro cômico, impiedoso, avassalador. Ele e o dinheiro, ambos invencíveis. Os músculos da ausência. Face a face a encenação da vestal. O impuro e as moiras. Todas em vestes escuras. De clara, apenas a vibração da carne desnuda e a ser devorada do porquinho nativo. O Brasil, em tudo. Partes dele. (SANTOS, 2002)
}

A irmã mais velha de Amélia, Francisca, expressa uma contradição, pois reza contra Amélia e ao mesmo tempo agradece-lhe pela insistência em tirá-la das terras de Cambuquira. Percebemos que o olhar estrangeiro de Amélia, como residente fora de seu país, influencia o olhar da família. A vida das irmãs do interior de Minas Gerais é vista como "simples" e "atrasada" a partir de uma perspectiva externa, possibilitada pela distância entre o focalizador (Amélia) e o ambiente focalizado (o interior mineiro). Na fala seguinte, Francisca mostra como o olhar estrangeiro da irmã lhe ajudou a compreender melhor a condição de subalternidade em relação aos valores da "civilização": 
- Às vezes eu tenho a impressão que faltam só dois minutos para fugir de tudo isso aqui. Sei lá, essa viagem, assim, para encontrar Amélia, parece que foi inventada por mim. Peço para Deus para não mudar nada aqui, para que Amélia não me tire daqui. Rezo para que alguma desgraça aconteça para Amélia. Depois vai indo, vai indo, e eu acabo a reza agradecendo a Amélia por me tirar daqui. Eu nunca tinha percebido que tinha essa vontade de sair daqui. ${ }^{6}$

Amélia, como um espaço conflitante de poder, atravessado por questões de gênero e cultura, demarca um ambiente de personagens femininas na zona de contato, conceito de Mary Pratt para designar o local caótico das negociações linguísticas, políticas e culturais de indivíduos separados por descontinuidades históricas e geográficas. Nesse espaço fronteiriço da zona de contato perpassa durante todo o tempo um discurso colonial e eurocêntrico, que faz da atriz Sarah Bernhardt seu principal representante, já que se recusa a aceitar os modos e costumes das irmãs mineiras, em defesa da superioridade cultural de seu próprio povo. Nas palavras de Souza podemos perceber claramente como isso acontece:

\begin{abstract}
As estratégias discriminatórias do discurso colonial baseiam-se na instauração de um mito de origem (a supremacia absoluta da raça colonizadora) inscrito numa recusa radical de alteridade e de hibridismo. Essa recusa procura transpor a duplicidade e o hibridismo no processo da construção da identidade instaurando um sujeito "puro" e monológico; contraditoriamente, porém, essa estratégia tenta eliminar as brechas ou diferenças essenciais para a construção da identidade do sujeito. (...). (SOUZA, 2004, p. 122-123)
\end{abstract}

A zona de contato, como fissura marcada pela presença constante do Outro em processo de negociação - em que as fronteiras são pensadas menos como barreiras, mas como instâncias permeáveis -, é vista como o local onde "as fronteiras são trazidas para o centro da discussão, enquanto centros homogêneos são deslocados para as margens." (PRATT, 1999, p. 13). Por isso, é possível analisar Amélia como um espaço de negociação e resistência a um discurso que se pretende ao mesmo tempo eurocêntrico e colonial, uma vez que Sarah Bernhardt tenta a todo o tempo impor sua cultura, sua língua e tudo aquilo que considera marca do homem civilizado. " - Olha só onde é que ela vive, cheia de coisa, de bicho, de pano!" 7 , relata Francisca, ao reclamar da falta de pagamento pelo trabalho executado e pelo sumiço da herança deixada por Amélia. O

\footnotetext{
${ }^{6}$ Fala de Francisca, personagem interpretada pela atriz Miriam Muniz, em diálogo com a irmã Oswalda, interpretada por Camila Amado, e com a criada Maria Luiza, interpretada pela atriz Alice Borges. Amélia, Cena 02. DVD Vídeo Filmes.

7 Amélia, Cena 13. DVD Vídeo Filmes.
}

Anuário de Literatura, ISSNe: 2175-7917, vol. 14, n. 1, 2009, p. 54 
dinheiro que se quer conquistar e que não aparece faz Francisca e Oswalda tomarem Sarah como a ladra estrangeira que veio ao Brasil para ferir e roubar. Em contrapartida, a atriz afirma, utilizando o argumento de que as três irmãs são verdadeiras sanguessugas por quererem tomar-lhe o saber, a força, a arte, as rendas, o perfume e o dinheiro, símbolos que demarcam o poder numa cultura "civilizada": "Doravante vocês dormirão no porão, dormirão sob seus cobertores podres, e comerão as pocarias às quais estão acostumadas e terminarão o que ainda resta para fazer sozinhas e caladas! (...) Olhem para mim e olhem para vocês. Vocês são inação, preguiça e destruição." 8 Nesta passagem, repetem-se os estereótipos do brasileiro como um ser atrasado e preguiçoso. Além disso, mesmo sendo uma atriz em plena crise profissional, Sarah Bernhardt coloca-se numa posição superior em relação às irmãs mineiras, dada a sua condição de mulher que integra o círculo dos sujeitos bem-sucedidos do mundo "civilizado".

$\mathrm{Na}$ concepção de Sarah, só é civilizado o sujeito que preenche alguns requisitos, dentre os quais estão a posse do conhecimento, da beleza e de bens materiais. Como assinala Santos: "Em desacordo, apesar dos esforços, em relação às convenções da civilidade, extraviados entre a seda e a chita, expomo-nos, no filme, tanto ao ridículo da beleza quanto ao inverso: à beleza do ridículo.” (SANTOS, 2002). Segundo esta concepção, as mulheres mineiras que se alimentam com as mãos e preparam sua própria refeição dentro do quarto de hotel são vistas como "porcas etruscas", o que faz cair por terra, perante a atriz francesa, a imagem do belo selvagem. De acordo com Caroline Brown, os europeus pensavam a terra desconhecida como paraíso onde habitavam povos selvagens, mais tarde vistos como "belos", dado o exotismo do cenário luxuriante dos trópicos: "Luxuriant with flora, dripping with moisture, opulent yet rough and largely uncharted, it is the paradise envisioned by Europeans in their imaginings of unclaimed foreign territories. (BROWN, 2003, p. 12). O imaginário formulado pelos europeus com relação à América deu origem ao Mito do Eldorado", a tão desejada "terra onde corre leite e mel”. Em Amélia, no entanto, há a desconstrução desse paraíso mítico projetado sobre o Novo Mundo.

Ligada à noção de paraíso, a figura do belo selvagem está relacionada ao estereótipo do índio criado no Romantismo e disseminado em toda a literatura deste período. Só se valorizavam os indígenas que apresentassem traços “morais” de acordo

${ }^{8}$ Trecho da fala de Sarah Bernhardt, em diálogo com Francisca, Oswalda e Maria Luiza. Amélia, Cena 13. DVD Vídeo Filmes.

${ }^{9} \mathrm{O}$ Eldorado, lugar mítico de riquezas fáceis e abundantes, é provavelmente o mais conhecido dos muitos mitos que alimentaram o desejo de descoberta dos conquistadores europeus no século XVI. 
com o pensamento do homem branco civilizado, como a força, a coragem e a honra; caso contrário, eram tidos como meros selvagens. A imagem das irmãs, como "belas selvagens", projetada em Sarah por intermédio de Amélia, não se legitima quando a atriz francesa passa a conviver com elas no hotel e no teatro. O conceito estético de "belo" de acordo com a concepção eurocêntrica de Sarah a faz ter horror ao paraíso, como assinala Santos:

De imediato reconhece Sarah o horror do paraíso (o sequer saber trepar, o mundo das bundas e seu caráter tedioso, o inóspito e insuportável mito da abundância, o tédio da natureza crua e inativa). Diz Sarah para as irmãs, repetindo os mitos que a antecedem: vocês consistem na inação (os dois sentidos). E o que é dito, nas próprias cenas, se desmonta; há, pois, resposta de vária ordem, há contrariedades, medições e lutas. (SANTOS, 2002)

O horror ao paraíso é manifestado na fala de Sarah quando afirma perante as irmãs mineiras que as "belas selvagens" não existem. Diante disto, as irmãs respondem categoricamente: “ - Existimos sim, madame!"10 Afirmar a não-existência de sujeitos que não estão no centro de poder de onde ecoa a voz que profere esta afirmação implica em negar toda a cultura que lhe é estranha. Essa negação da diferença do outro é justamente o que está no cerne da formação do estereótipo e do discurso colonial representado pela personagem de Sarah Bernhardt. Mesmo assim, Amélia, com toda a dificuldade de comunicação entre as personagens, que se exprimem utilizando-se do espanhol ao italiano, é visto como um espaço de negociação intermitente onde a língua funciona como algo que comunica hierarquias mais profundas. Mesmo estando em terras brasileiras, a atriz francesa e sua criada relutam em falar a língua portuguesa e utilizam o francês como uma espécie de idioma eleito para comunicar o poder do sujeito "colonizador".

No filme, não há somente hierarquia de um grupo em relação a outro - com a supremacia do grupo civilizado (Sarah e Vincentine) -, mas no próprio seio de cada grupo. Se analisarmos a condição das criadas, Vincentine e Maria Luiza, percebemos que elas têm a função de servir. A primeira, fruto de uma cultura letrada que preza pela classe e pelo saber, ostenta sua servilidade diante de uma atriz famosa. A seu modo, temos a criada mineira, Maria Luiza, que com ares de certa sensualidade também

${ }^{10}$ Amélia, Cena 13. DVD Vídeo Filmes. 
presta-se a servir Francisca e Oswalda na vida simples da fazenda. Como descreve Santos:

As criadas, personagens imprescindíveis em ambas as comédias, lá estão: a criada cheia de carne e busto, em sua sensualidade dispersa e oca; a criada seca, a cópia, a frieza espantada. Da comédia, patroas e criadas, o fascínio entre mulheres, a atração pelas fórmulas oponentes das classes. A perturbação entre elas, disputa, tagarelice, a conquista. Que se chame de vida ou de amor. (SANTOS, 2002)

Diferente de Vincentine, Maria Luiza dorme no chão e recebe bofetões de Francisca como reprimenda, em detrimento da criada de Sarah, que tem de conviver com os berros histéricos da atriz, como se isto consistisse numa forma mais "civilizada" para o ato de mandar.

Quanto ao espaço de negociação do filme: “O teatro, o seu país, a sua terra. Jamais estará consciente de estar senão em cena.” (SANTOS, 2002). É no espaço cênico do teatro que a atriz francesa, as irmãs mineiras e as respectivas criadas tentam negociar as diferenças. Nenhuma delas está no seu lugar de residência fixa, é no entre-lugar do teatro que as mulheres atuam. Diante disto, podemos pensar no teatro como o próprio espaço cênico, o lugar neutro onde as diferenças da vida real são sucumbidas para dar lugar ao fíctício e ao ilusório? Ou o teatro pode prestar-se como um espaço de dominação, uma vez que é o lugar de atuação da atriz? Parece-nos que a segunda opção é a mais pertinente para analisarmos a questão dos fluxos de poder que se instauram com a mudança para o teatro, pois no filme esta mudança é impulsionada pela própria Sarah, que não consulta as irmãs mineiras em nenhum momento. A atriz apodera-se do seu espaço de excelência para impor seu estilo de vida, além de suas concepções políticas e ideológicas

Contrapondo-se a toda forma de imposição cultural, a declamação do poema ${ }^{11}$ de Gonçalves Dias por Francisca demonstra o ideal romântico de valorização da pátria. É um discurso ressentido que perpassa no Romantismo a ideia de compensação, pois, pensava-se que era preciso procurar no exotismo brasileiro elementos que servissem de compensação para o estado de barbárie do Brasil em relação ao centro europeu. Nesse sentido, elegem-se a natureza exuberante e a figura do índio como símbolos da identidade nacional. Por isso, quando Francisca vale-se do mesmo pensamento romântico para valorizar seu país, ela acaba por afirmar, por meio da comparação, a

\footnotetext{
${ }^{11}$ Trata-se do poema épico I-Juca Pirama, que relata a prisão de um guerreiro tupi por uma tribo antropófaga.
} 
posição inferior do Brasil perante a cultura do colonizador. Além disso, a cena em que ela declama o poema perante a figura avassaladora de Sarah Bernhardt pode ser vista como uma "revanche" em relação ao olhar norteador eurocêntrico. Trata-se de um grande momento de resistência contra todas as tentativas de Sarah, que tenta a todo momento subjugar um modo de estar no mundo, a cultura comezinha das irmãs mineiras.

Na cena final de Amélia, quando o mesmo poema é utilizado na apresentação feita em Paris com a participação das três mulheres mineiras e com a tentativa de representação do cenário indígena presente no Brasil, temos a tradução do poema da sua língua de origem para o francês. Notamos uma ironia com relação ao olhar eurocêntrico de Sarah, já que temos a repetição dos mesmos estereótipos pelos quais o Brasil é conhecido internacionalmente. Não poderíamos deixar de assinalar o olhar irônico da diretora, que inseriu as mulheres mineiras no espetáculo apresentado em Paris como simples peças de decoração do cenário. As mineiras não atuam em momento algum da peça, mas têm sua cultura representada mesmo que de forma estereotipada, num espaço de poder da Europa no início do século XX, quando a direção dos fluxos culturais dá-se normalmente no sentido Europa -> Brasil (e não o contrário). De acordo com a diretora Ana Carolina, em entrevista ao jornal O Estado de São Paulo:

\footnotetext{
"As mulheres rústicas representam uma civilização com seus códigos, suas músicas, mumunhas, suas comidas e meios de viver. Mas quando entra a civilização imperialista, e para nós àquela época a perfeição era caminhar para o afrancesamento, esta destrói a outra." O que sobra? "A barbárie", responde a cineasta.

(http://www.terra.com.br/cinema/noticias/2000/07/19/000.htm)
}

Da mesma forma que Amélia lida com estereótipos, tomando o conceito de estereótipo de Homi Bhabha - que o define como sendo uma representação falsa da realidade que rejeita a presença do Outro, além de negar o processo de hibridismo na construção da identidade - podemos enxergar também em The Piano marcas da fixação em um objeto a fim de substituir uma falta. Essa fixação num objeto com o objetivo de compensar a falta percebida da plenitude é o que a psicanálise chama de fetiche, de cuja noção Bhabha se apropria para pensar a formação dos estereótipos. Segundo Souza:

Como o fetiche, o estereótipo, além de ser uma simplificação e uma representação falsa da realidade, é também uma forma de representação que rejeita a alteridade; ele nega o jogo da diferença, presente no processo relacional da construção da identidade e, com isso, nega a necessidade da 
alteridade e do hibridismo na construção da identidade, pressupondo que haja identidades puras, não-híbridas. (SOUZA, 2004, p. 123)

Se em The Piano perpassa o pensamento típico do discurso colonial, que prevê que os europeus são um povo que tem cultura em detrimento dos aculturados selvagens - com quem Stewart e os outros colonizadores negociam a todo momento -, em Amélia também temos a repetição do estereótipo do "belo selvagem", com o qual a própria Sarah Bernhardt se esbarra e tenta desconstruir. Além disso, em Amélia há uma cena de envolvimento da atriz francesa com um negro de porte robusto ${ }^{12}$, que simboliza o encontro da mulher branca europeia com a figura sensual do homem brasileiro. É o que Shohat e Stam analisam como sendo um olhar que valoriza a liberdade da libido, mas que, em contrapartida, apresenta um racismo velado:

\begin{abstract}
Quando estereótipos antinegros (sua bestialidade repulsiva, por exemplo) são registrados como positivos (a liberdade da libido), isso nos diz mais sobre a imaginação erótica branca do que sobre o objeto de sua fascinação. O elogio da agilidade física do negro é tacitamente acompanhado pela afirmação de sua suposta incapacidade mental. (SHOHAT e STAM, 2006, p. 48)
\end{abstract}

$\mathrm{Na}$ cena em que aparecem Sarah e as mulheres mineiras se banhando ${ }^{13}$, a atriz pede ao personagem Lano que faça uma comparação entre ela e Amélia. Lano afirma que Amélia era "brasileira" e, logo em seguida, apalpa as nádegas da criada Vincentine, deixando implícita a ideia do habitante brasileiro como um ser marcado pela sensualidade e pela afeição ao sexo. Esse pensamento agenciado na cena, da mesma forma que apresenta o estereótipo da sensualidade do sujeito brasileiro como algo positivo, escamoteia uma parcela de discriminação, como nos mostra Shohat e Stam na citação acima.

Em Amélia, a diretora Ana Carolina trabalha predominantemente com mulheres. O gênero é somente um dos fatores que compõe o processo de tensão no filme, que também é atravessado por questões de classe e cultura; sem falar no deslocamento das personagens, fator imprescindível no processo de tradução cultural, conforme o quer Bhabha. Segundo ele, é na "travessia" por entre os espaços culturais intersticiais que se constroem novos valores, como ocorre com as personagens diaspóricas de Amélia e de The Piano, que negociam suas diferenças fora do seu local

${ }^{12}$ Amélia, Cena 08. DVD Vídeo Filmes.

${ }^{13}$ Amélia, Cena 10. DVD Vídeo Filmes. 
de origem. Ada, a mãe escocesa do segundo filme, migra de sua terra natal para viver em um meio marcado pela presença opressora do masculino, enquanto as três matutas mineiras são vítimas da "civilização" dentro do seu próprio país. Elas podem ser comparadas, de certa forma, à população maori de The Piano, dado o processo de marginalização dentro dos limites da própria terra natal.

Se o filme de Jane Campion deixa entrever que a subalternidade de Ada (motivada principalmente por questões de gênero) é levada até as últimas consequências - mesmo que esta mulher seja uma representante da cultura branca europeia -, a narrativa cinematográfica da diretora brasileira Ana Carolina mostra que a subalternidade em Amélia está atravessada, sobretudo, por questões de classe. Ada tem seu dedo mutilado por Stewart, em detrimento de Sarah Bernhardt, que é vítima da ação cômica e ao mesmo tempo ressentida das irmãs mineiras. A mutilação do corpo de Ada parte do opressor masculino, enquadrado no centro do poder, enquanto a "mutilação" verificada na atriz francesa parte da classe subalterna, que se vinga às custas de parte do corpo da mulher civilizada.

Em ambos os filmes analisados, verificamos como o discurso colonial propaga-se dos centros de poder europeus em direção às periferias, sejam estas representadas por mulheres, indígenas ou por habitantes do Terceiro Mundo. Mesmo que o eurocentrismo tenha por objetivo "normalizar" as hierarquias existentes, podemos perceber que elas não existem a priori, pois são construídas a partir de intensas negociações. Além disso, o processo de tradução cultural, muito produtivo para a análise de cinematografias que apresentam sujeitos em trânsito, mostra que a relação entre culturas não se efetiva de forma unidirecional e que os fluxos culturais são sempre atravessados por questões de raça, classe e gênero, como evidenciam os dois filmes abordados.

\section{REFERÊNCIAS}

BAKHTIN, Mikhail. Problemas da Poética de Dostoiévski. Tradução de Paulo Bezerra. Rio de Janeiro: Ed. Forense Universitária, 2005.

BROWN, Caroline. The Representation of the Indigenous Other in Daughters of the Dust and The Piano. NWSA Journal, Volume 15, Number 1, Spring 2003, pp. 1-19. 
CAMPION, Jane. The Piano. West Hollywood, CA: Miramax Films. 1993. Motion Picture.

CAROlinA, Ana. Amélia. Cristal Cinematográfica, Videofilmes, 2000. Acesso em: 01 Set. 2009.

- Cineasta retoma após 12 anos com Amélia. Disponível em: $<$ HTTP://www.terra.com.br/cinema $>$ Acesso em: 01 Set. 2009.

PRATT, Mary Louise. A crítica na zona de contato: nação e comunidade fora de foco. Trad. Felipe Guimarães Soares. Travessia: Revista de Literatura, n. 38, 1999, p. 7-29. SANTOS, Roberto Correa dos. Amélia de Ana Carolina - Senhores, Eu vi . In: Cátedra Padre Antônio Vieira de Estudos Portugueses. Revista Semear 6. 2002. Disponível em: $<$ http://www.letras.pucrio.br/Catedra/revista/6Sem_10.html> Acesso em: 01 Set. 2009. SHOHAT, Ella; STAM, Robert. Crítica da imagem eurocêntrica. Trad. Marcos Soares. São Paulo: Cosac Naify, 2006.

SOARES, Cleuza Maria. Interseccionalidade de diferenças: feminismo entre fronteiras e espaços de poder. In: Fazendo Gênero 8 - Corpo, violência e poder. Florianópolis:

UFSC, 2008. Disponível em:

$<$ http://www.fazendogenero8.ufsc.br/sts/ST72/Cleuza_Maria_Soares_72.pdf $>$ Acesso em: 01 Set. 2009.

SOUZA, Lynn Mario T. Menezes de. Hibridismo e tradução cultural em Bhabha. In: Benjamin Abdala Junior (org.), Margens da Cultura: Mestiçagem, hibridismo e outras misturas. São Paulo: Boitempo Editora, 2004. p. 113-134.

STAM, Robert. Introdução à teoria do cinema. São Paulo: Papirus, 2003. 